\title{
Identification, characterization and functional analysis of AGAMOUS subfamily genes associated with floral organs and seed development in Marigold (Tagetes erecta)
}

Chunling Zhang ${ }^{1}$, Ludan Wei ${ }^{1}$, Wenjing Wang ${ }^{1}$, Wenquan $\mathrm{Qi}^{1}$, Zhe CaO ${ }^{2}$, Hang Li ${ }^{1}$, Manzhu Bao ${ }^{1}$ and Yanhong $\mathrm{He}^{1 *}$

\begin{abstract}
Background: AGAMOUS (AG) subfamily genes regulate the floral organs initiation and development, fruit and seed development. At present, there has been insufficient study of the function of $A G$ subfamily genes in Asteraceae. Marigold (Tagetes erecta) belongs to Asteraceae family whose unique inflorescence structure makes it an important research target for understanding floral organ development in plants.

Results: Four AG subfamily genes of marigold were isolated and phylogenetically grouped into class C (TeAG1 and TeAG2) and class D (TeAGL11-1 and TeAGL11-2) genes. Expression profile analysis demonstrated that these four genes were highly expressed in reproductive organs of marigold. Subcellular localization analysis suggested that all these four proteins were located in the nucleus. Protein-protein interactions analysis indicated that class $C$ proteins had a wider interaction manner than class D proteins. Function analysis of ectopic expression in Arabidopsis thaliana revealed that TeAG1 displayed a C function specifying the stamen identity and carpel identity, and that TeAGL11-1 exhibited a D function regulating seed development and petal development. In addition, overexpression of both TeAG1 and TeAGL11-1 leaded to curling rosette leaf and early flowering in Arabidopsis thaliana.
\end{abstract}

Conclusions: This study provides an insight into molecular mechanism of $A G$ subfamily genes in Asteraceae species and technical support for improvement of several floral traits.

Keywords: Marigold, Floral organs, MADS-box genes, AGAMOUS subfamily genes, Functional analysis

\footnotetext{
* Correspondence: hyh2010@mail.hzau.edu.cn

'Key Laboratory of Horticultural Plant Biology, Ministry of Education; College

of Horticulture and Forestry Sciences, Huazhong Agricultural University,

Shizishan Street No. 1, Wuhan 430070, China

Full list of author information is available at the end of the article
}

(c) The Author(s). 2020 Open Access This article is licensed under a Creative Commons Attribution 4.0 International License, which permits use, sharing, adaptation, distribution and reproduction in any medium or format, as long as you give appropriate credit to the original author(s) and the source, provide a link to the Creative Commons licence, and indicate if changes were made. The images or other third party material in this article are included in the article's Creative Commons licence, unless indicated otherwise in a credit line to the material. If material is not included in the article's Creative Commons licence and your intended use is not permitted by statutory regulation or exceeds the permitted use, you will need to obtain permission directly from the copyright holder. To view a copy of this licence, visit http://creativecommons.org/licenses/by/4.0/ The Creative Commons Public Domain Dedication waiver (http://creativecommons.org/publicdomain/zero/1.0/) applies to the data made available in this article, unless otherwise stated in a credit line to the data. 


\section{Background}

Flowers are the reproductive organs of a plant, which are regarded as an important morphological innovation in plant evolution. The MADS-box transcription factors are key elements in floral organ identity [1, 2], fruit and seed development [3, 4], and leaf and root development as well $[5,6]$. Based on the genetic studies, a well-known $\mathrm{ABCDE}$ model is introduced to explain genetic regulation in floral organ determination. In this model, class $\mathrm{A}$ and $\mathrm{E}$ genes determine the sepals; class $\mathrm{A}, \mathrm{B}$, and $\mathrm{E}$ genes specify the petals; class $B, C$, and $E$ genes regulate the stamens fate; class $C$ and $E$ genes control the carpel formation; and class D and $\mathrm{E}$ genes direct the ovule development [7, 8]. The AGAMOUS (AG) subfamily genes belonging to MADS-box classes $\mathrm{C} / \mathrm{D}$ are involved in the regulation of floral organ, floral meristem, and fruit development. Previous reports demonstrated that $A G$ subfamily genes are most likely to be arose from several paraphyletic lineages with multiple whole-genome duplication events (WGDs) in flowering plants, leading to possible subfunctionalization [9-12]. The first WGDs probably result in the generation of $A G$ (class $C$ ) lineage and AGAMOUSLIKE11(AGL11, class D) lineage $[10,11]$. The $A G$ lineage then undergoes the second WGDs in core eudicots, resulting in two sub-clades of euAG and PLENA (PLE) $[9,10]$.

The genes in $A G$ lineage determining the floral meristem development and reproductive organ (stamen and carpel) identity [13] were firstly identified in Arabidopsis (Arabidopsis thaliana, AG) [13] and Antirrhinum (Antirrhinum majus, PLE) [10]. In Arabidopsis, the class C genes prevent the class A genes from functioning in inner whorl floral organs, which is clearly supported by reducing the $A G$ expression in Arabidopsis, resulting in homeotic mutation of reproductive organs such as petallike stamens and sepal- or petal-like carpels [14-16]. The function of $A G$ lineage genes has been previously characterized in other eudicot species including Chrysanthemum (Chrysanthemum morifolium) [17], Petunia (Petunia hybrida) [18], Populus (Populus trichocarpa) [2], and also in monocot species such as Rice (Oryza sativa) [19].

Then, the FLORAL BINDING PROTEIN7 (FBP7) and FLORAL BINDING PROTEIN11 (FBP11) regulating ovule identity in petunia were determined as class $D$ genes, and these two genes belong to the AGL11 lineage $[20,21]$. In Arabidopsis, there are three D class genes, named SEEDSTICK (STK; formerly known as AGL11), SHATTERPROOT1 (SHP1), and SHATTERPROOT2 (SHP2), which redundantly overlap in their function in regulating ovule development [22-24]. This is verified by the phenotypes of single gene and triple gene mutants. In triple mutant, integuments are transformed into carpelloid structures, and female gametophyte development is interrupted just after megasporogenesis.
However, in stk single mutant, only the ovule funiculus is larger than that of the wild type, and the mature seeds are not detached from the silique [24-27]. In addition, the similar phenotype changes have been reported in cultivated Grapevine (Vitis vinifera) [28] and Populus [2], indicating that STK/AGL11 has a conservative function in regulating the ovule development.

Asteraceae is one of the largest plant families of flowering plants, which bears a unique head-like inflorescence consisting of hundreds of ray florets and disk florets. For head-like inflorescence, the outer are the sterile ray florets without stamen, and the inner are the fertile disk florets with complete four whorl organs. There are multiple floret morphological traits existing in a single inflorescence, such as fertility, symmetry, and organ fusion. Therefore, Asteraceae provides an unparalleled opportunity to study the genetic regulation of the above-mentioned phenomena. Previous studies have revealed that the auxin and genes $L F Y$ and $U F O$ are involved in pattern formation of the head flower, and that CYC-like genes regulate the flower symmetry [29-31]. The MADS-box family genes play an important role in the regulation of floral meristem and floral organ development, and their functions in regulating the formation of head-like inflorescence in Asteraceae have been a research hotspot. Until now, the functions of class B genes have been reported in many Asteraceae species [32-34], but there have been few reports on AGAMOUS subfamily genes in Asteraceae species. Up to now, the $A G$ gene functions in Gerbera (Gerbera hybrid) [35], Chrysanthemum [36], and Sunflower (Helianthus annuus) [37] have been reported, and the results reveal that $A G$ function in Asteraceae is conservative in specifying the stamen and carpel identity. Unlike $A G$ lineage genes, the functions of AGL11 lineage genes have not been reported in Asteraceae.

Marigold (Tagetes erecta) is a popular ornamental plant. As a member of Asteraceae family, marigold has typical head flower consisting of two morphologically distinct types with ray (sterile) florets in the periphery and disk (fertile) florets in the center. The growth period of marigold is $2-3$ months from sowing to flowering. In the evolutionary history of Asteraceae family, marigold undergoes a long evolutionary process, and it is located in a derived Calenduleae clade [38]. These characteristics make marigold an important plant in the study of floral organ development. Here, two AG lineage genes (TeAG1 and TeAG2) and two AGL11 lineage genes (TeAGL11-1 and $T e A G L 11-2)$ of marigold were cloned, their expression patterns were investigated, and their subcellular localization was determined. Yeast two-hybrid assay and ectopic transformation were conducted to predict the gene functions in the formation of floret organs and the development of seeds. 


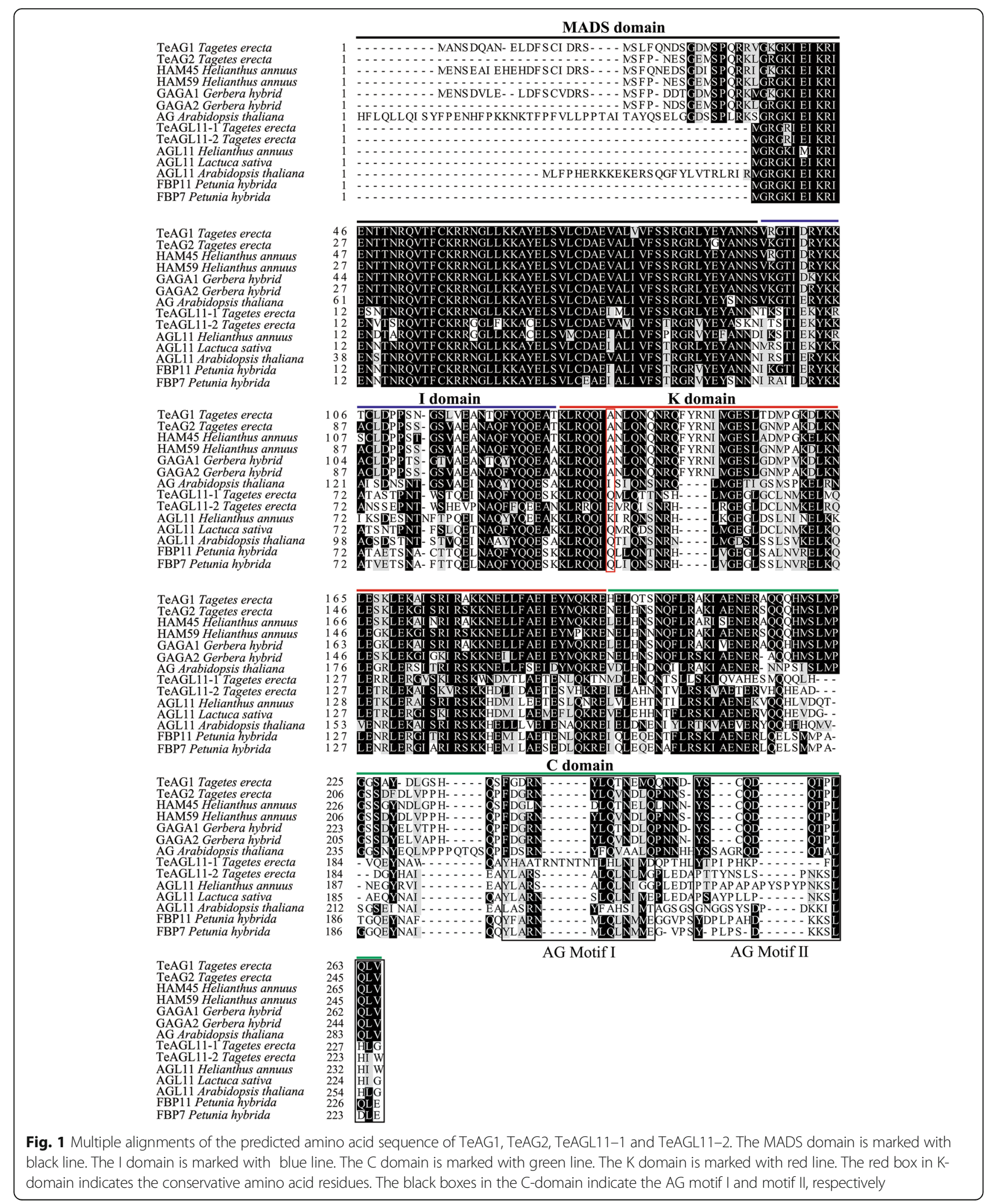




\section{Results}

Isolation and molecular characterization of marigold AGAMOUS subfamily genes

To study the functions of $A G$ subfamily genes in marigold, we amplified TeAG1 (991 bp), TeAG2 (837 bp), TeAGL11-1 (735 bp), and TeAGL11-2 (831 bp). Their sequences included the open reading fragment, partial 5' untranslated region and partial 3' untranslated region. Multiple alignment with other typical C/D proteins from model plants and Asteraceae species showed that these four proteins were typical MADS-box proteins containing MADS-domain, I-domain, K-domain with conservative amino acid residues, and AG motif I and AG motif II in C-terminal end (Fig. 1). Phylogenetic analysis using

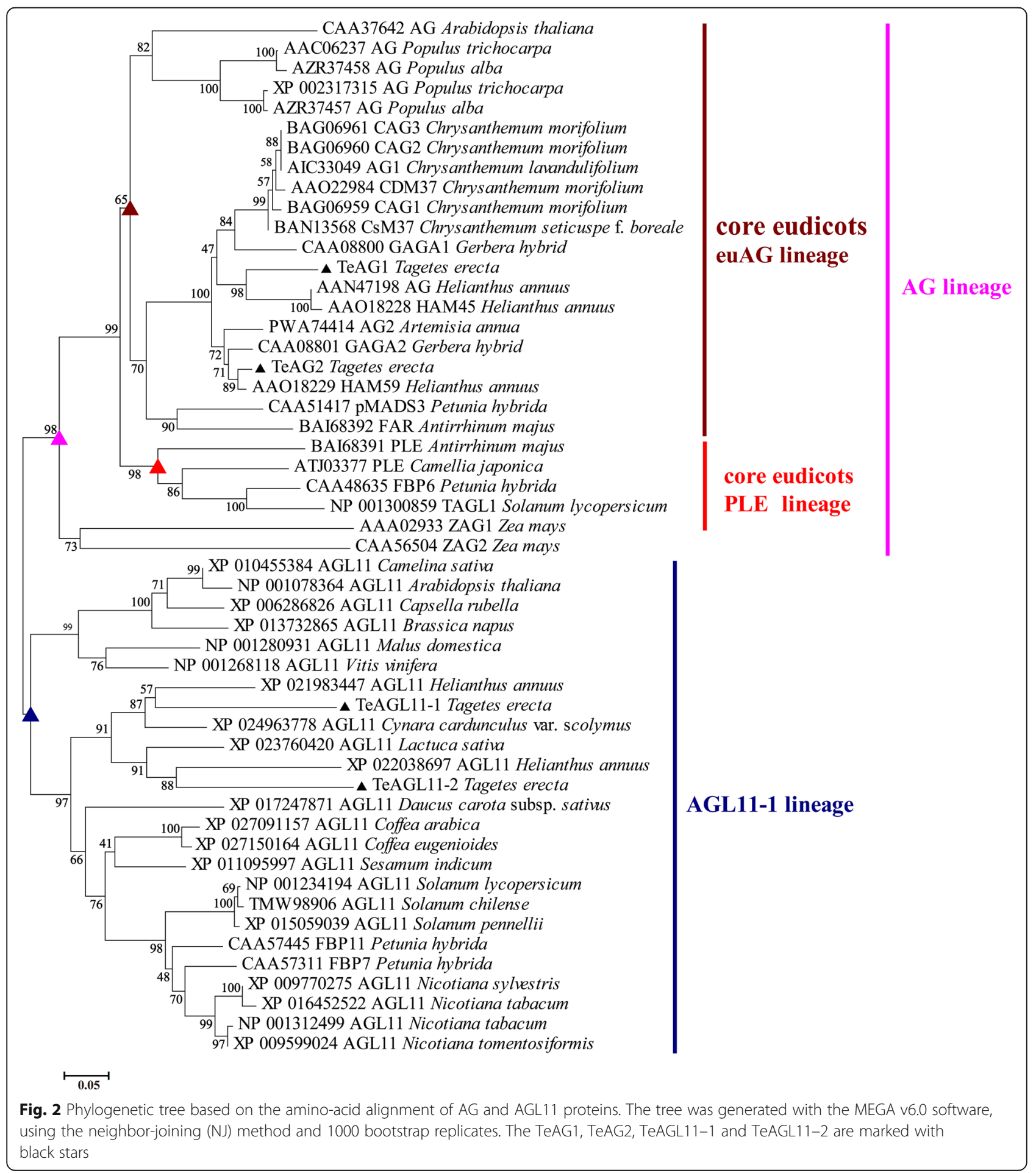


neighbor-joining (NJ) method showed that these proteins were divided into two main branches of AG and AGL11 lineages corresponding to the MADS-box class $\mathrm{C}$ and class $\mathrm{D}$ genes, respectively (Fig. 2). The first WGDs was found to have occurred during evolutionary history of marigold. Two C class proteins TeAG1 and TeAG2 were clustered to core eudicot euAG lineage, and two D class proteins TeAGL11-1 and TeAGL11-2 were clustered into AGL11 lineage (Fig. 2). TeAG1 and TeAG2 proteins are putative orthologs of Sunflower HAM45 and HAM59 proteins, respectively, both of which shared amino acid identity as high as over $85 \%$ (Table S2). TeAGL11-1 and TeAGL11-2 proteins shared high similarity with their orthologs Sunflowers HaAGL11-1 and HaAGL11-2 proteins with amino acid identity of 70.76 and $65.38 \%$, respectively (Table S3).

\section{Expression patterns of TeAG and TeAGL11 genes}

Here, qRT-PCR was conducted to investigate the expression patterns of the four genes in marigold. In order to determine whether genes' transcripts were stagedependent or not, we preliminarily detected their expression levels at four stages of floral buds (FB1-FB4). The qRT-PCR analysis showed that the transcript levels of TeAG1, TeAG2, and TeAGL11-2 showed an increase tendency during floral bud development, while the expression level of TeAGL11-1 was very weak and exhibited no significant changes in four floral bud development stages (Fig. 3a, Fig. S1, Table S6).

We further analyzed the expression levels of the four genes in vegetative tissues, and anthesis stage of flower organs (Fig. 3a, b, Fig. S1, Table S6). The results showed that these genes were highly expressed in floral organs.

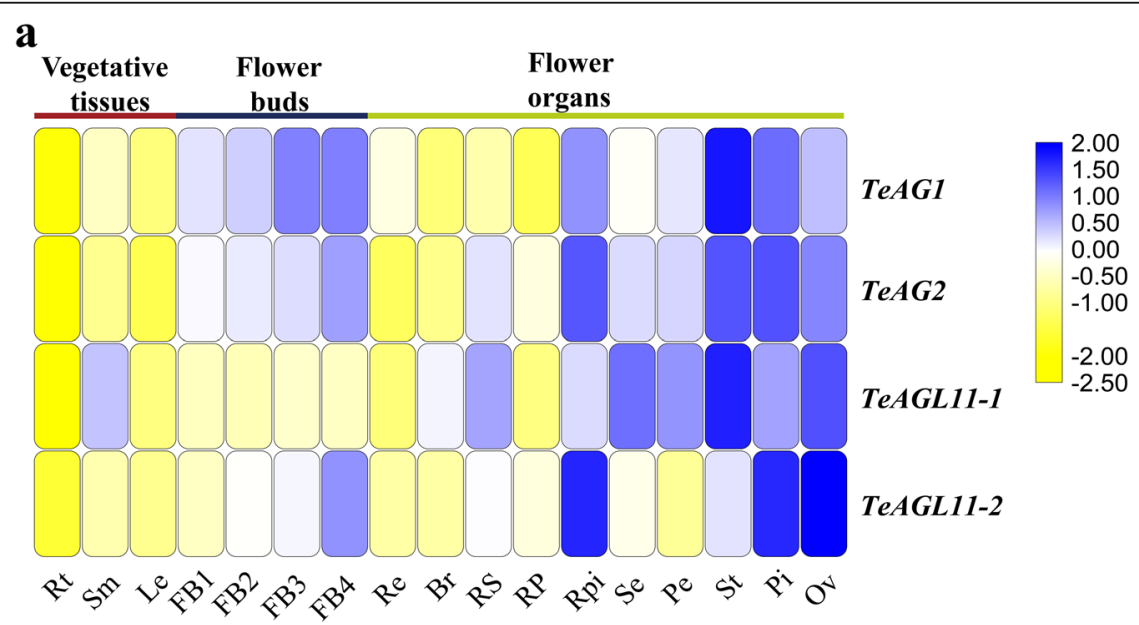

b
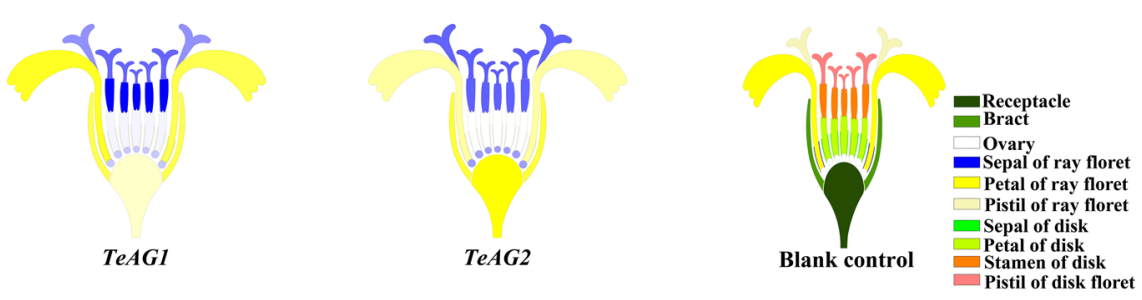

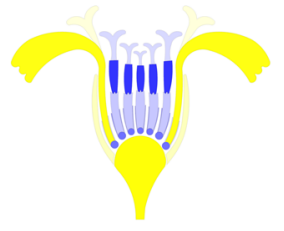

TeAGLII-1

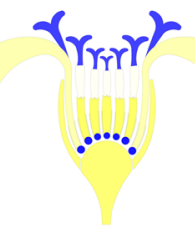

TeAGLI1-2

Fig. 3 Expression levels of TeAG and TeAGL11 genes in different tissues and organs of marigold. (a) Heatmap of relative expression of TeAG1, TeAG2, TeAGL11-1 and TeAGL11-2 genes by qRT-PCR in different tissues and organs. Rt: root; Sm: stems; Le: leaves; FB1-FB4: flower buds were 0-1 mm, 2-3 mm, 4-5 mm and 6-7 mm in diameter, respectively; Re: receptacle; Br: bract; RS: sepal of ray floret; RP: petal of ray floret; RPi: pistil of ray floret; Se: sepal of disk floret; Pe: petal of disk floret; St: stamen of disk floret; Pi: pistil of disk floret; Ov: ovary. (b) Heatmap of TeAG1, TeAG2, TeAGL11-1 and TeAGL11-2 genes in the inflorescence of marigold based on the relative expression by qRT-PCR. Blank control: structural model of capitulum in $T$. erecta, different colors represent different floral organs 


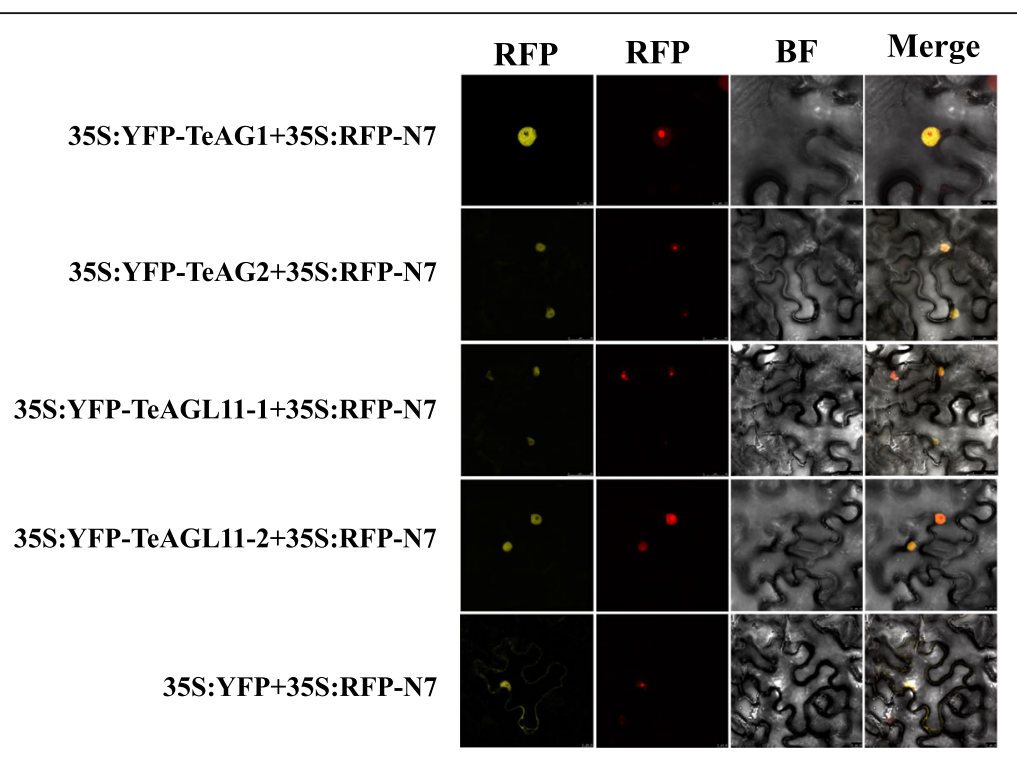

Fig. 4 Subcellular localization of the AGAMOUS-like subfamily proteins of marigold. These four fusion proteins were driven by 355 promoter and transiently expressed in tobacco leaf. Photographs were obtained with a confocal microscope. 35S:YFP as a negative control; 355 :RFP-N7 as a nucleus controls. YFP: yellow fluorescence; REP: red fluorescence; BF: bright field image; Merge: merged images of Bright, YFP and REP fields

The TeAG1 and TeAG2 were more preferentially expressed in reproductive organs (stamens, pistils and ovaries) than in sepals and petals. Interestingly, the transcript level of TeAG1 was significantly higher in stamens than in pistils and ovaries, while that of TeAG2 was higher in stamens and pistils than in ovaries. The expression patterns of the two AGL11 genes varied in floral organs. TeAGL11-1 had a wide expression region in disk florets, including sepals, petals, stamens, and pistils, whereas this gene was detected only in sepals and pistils of ray flowers, as well as in ovaries. Remarkably, the high expression level of TeAGL11-1 was detected in stamens. In contrast, the TeAGL11-2 was higher expressed in pistils, and ovaries than in stamens, sepals, and petals.

\section{Subcellular localization of TeAG and TeAGL11 proteins}

To gain an insight to the subcellular localization of these four genes, four fusion vectors 35S:YFP-TeAG1, 35S: YFP-TeAG2, 35S:YFP-TeAGL11-1, and 35S:YFPTeAGL11-2 were transiently co-transformed with $35 \mathrm{~S}$ :
RFP-N7 vector into the leaf of tobacco, respectively. The fluorescence signals of these four fusion vectors were mainly observed in the nucleus outside the nucleolus (Fig. 4).

\section{Protein interactions of TeAG and TeAGL11}

To confirm the interaction among the four proteins, the yeast two-hybrid experiment was performed. Selfactivation of BD constructs was assessed. The results indicated that no autoactivation was observed (Fig. S2a). Although TeAG1 and TeAG2 proteins shared a high similarity in sequences, their interaction manner with other AGAMOUS subfamily proteins were different. As shown in Table 1 and Fig. S2b, the TeAG2 formed heterodimers with TeAG1, TeAGL11-1, and TeAGL11-2, and formed homodimer with itself. However, the TeAG1 only interacted with TeAG2 and TeAGL11-1, but it formed no homodimer. The TeAGL11-1 and TeAGL11-2 showed a limited interactive ability with other AGAMOUS subfamily proteins. Neither homodimer nor heterodimer were formed through the

Table 1 Interactions of marigold TeAG and TeAGL11 proteins detected by yeast two-hybrid assays

\begin{tabular}{|c|c|c|c|c|c|c|}
\hline & AD-TeAG1 & AD-TeAG2 & AD-TeAGL11-1 & AD-TeAGL11-2 & AD-empty & AD-T7 \\
\hline BD-TeAG1 & - & ++ & ++ & - & - & I \\
\hline BD-TeAG2 & ++ & ++ & + & ++ & - & / \\
\hline BD-TeAGL11-1 & ++ & - & - & - & - & / \\
\hline BD-TeAGL11-2 & - & - & - & - & - & / \\
\hline BD-empty & - & - & - & - & - & / \\
\hline BD-53 & / & / & / & / & / & / \\
\hline
\end{tabular}

Note: ++, strong interaction; +, weak interaction; -, no interaction, / not determined 

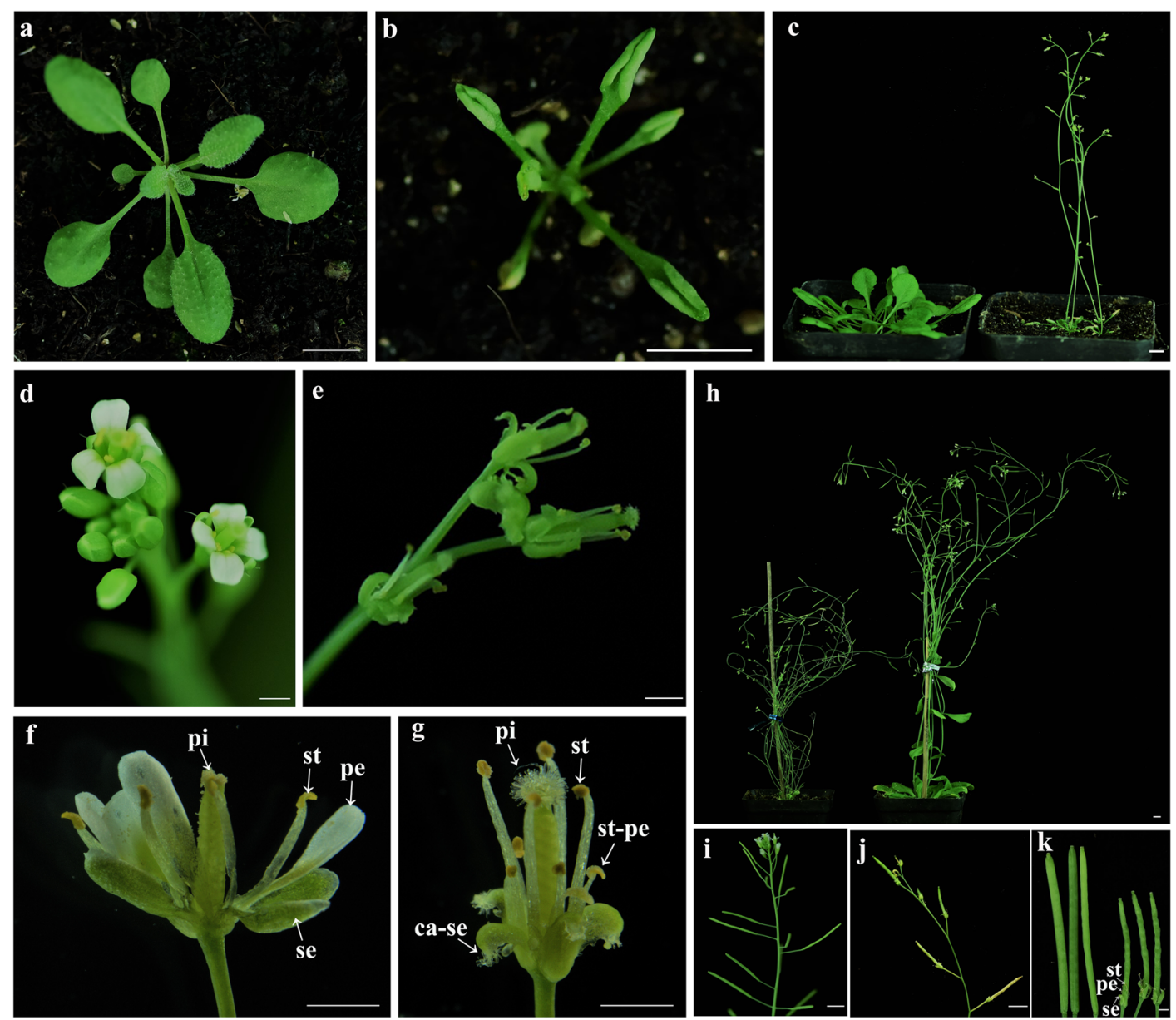

$\mathbf{L}$

Rosette leaves (n)
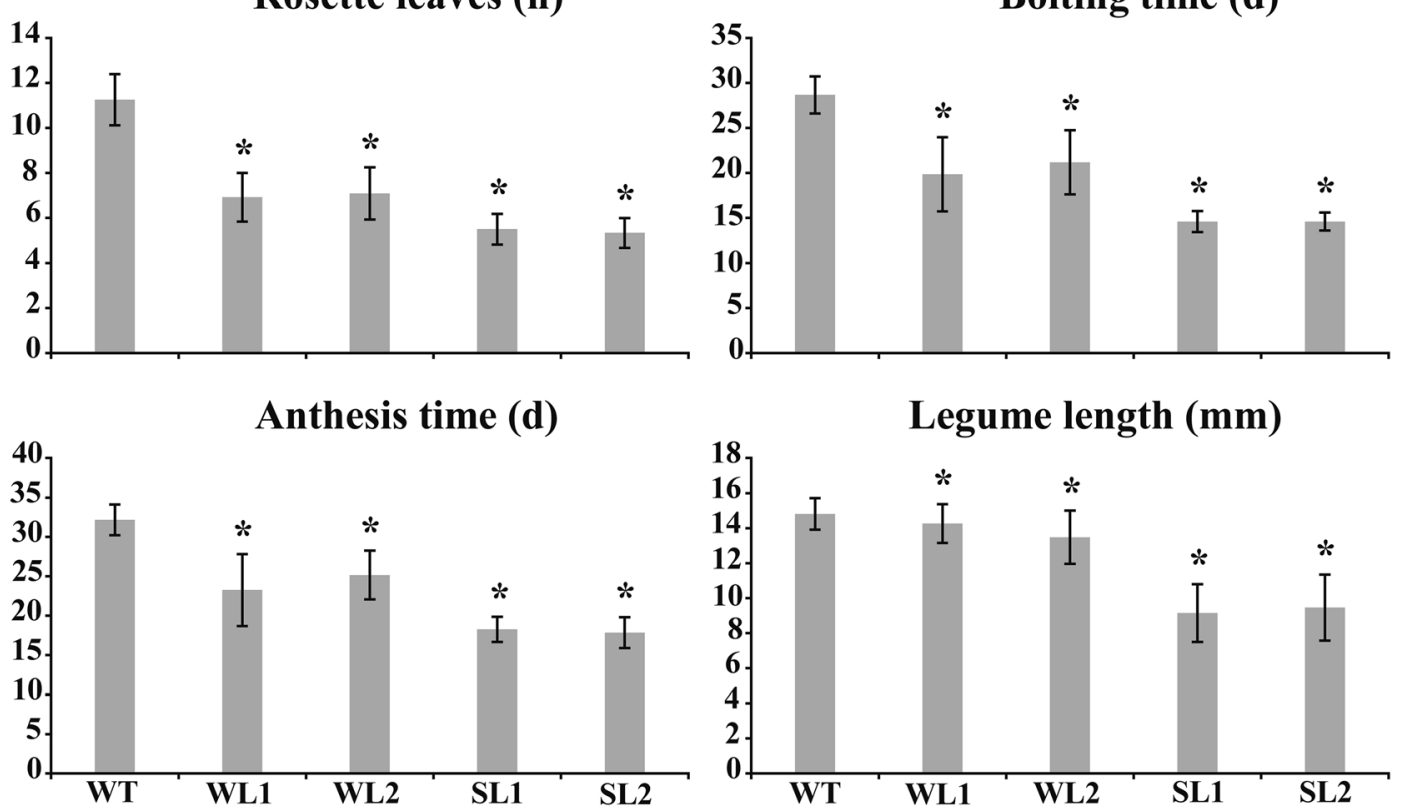

Fig. 5 (See legend on next page.) 
(See figure on previous page.)

Fig. 5 Abnormal morphology of transgenic Arabidopsis plants of constitutively expressed TeAG1 gene. a-k The morphological trait of SI-TeAG1 lines and wild-type lines. (a) The wild-type seedling; (b) The transgenic seedlings with severe curled rosette leaves; (c) Wild-type (left) and early flowering transgenic plant (right); (d, $\mathbf{f})$ normal flowers of wild-type; $(\mathbf{e}, \mathbf{g})$ mutant flowers of the transgenic plant; (h) Wild-type (right) and the dwarfing transgenic plant (left); (j, k) The siliques of transgenic lines are short and yellowish-green with persistented sepals, petals and stamens compared to those from wild-type (i). se: sepal; pe: petal; st: stamen; pi: pistil, ca-se: carpelloid sepals; st-pe: stamen-like petal; WT1: wild-type line 1; WT2: wild-type line 2; WL1: WI-TeAG1 line 1; WL2: WI-TeAG1 line 2; SL1: SI-TeAG1 line 1; SL2: SI-TeAGL1 line 2. a-c, bar $=5 \mathrm{~mm}, \mathrm{~d}-\mathrm{k}, \mathrm{bar}=1 \mathrm{~mm}$. (I) Statistics for main morphological traits of the control and transgenic plants, ${ }^{*}$ significant difference at $P<0.05$

interaction between AGL11-1 and AGL11-2. TeAGL11-1 and TeAGL11-2 interacted with TeAG2 unidirectionally. In addition, TeAGL11-1 strongly interacted with TeAG1, while TeAGL11-2 had no ability to interact with TeAG1.

\section{Dramatic effect of overexpression of TeAG1 in Arabidopsis on sepal and petal identity}

To further study the functions of TeAG1 and TeAG2, functional analyses were performed using ectopic expression in Arabidopsis. Eighteen 35S:TeAG1 transgenic lines and twenty-three 35S:TeAG2 transgenic lines were obtained. Transcript levels of TeAG1 and TeAG2 were further analyzed by semi-quantitative RT-PCR with the flower cDNA as templates (Fig. S3a, b). The 35S:TeAG2 transgenic lines did not show any evident morphological changes, compared with the wild type. However, five of the 35S:TeAG1 transgenic lines displayed severe phenotypes (named Sl-TeAG1), seven showed weak phenotypes (named Wl-TeAG1), and six had no remarkable phenotypic changes. Compared with the wild type, SlTeAG1 and Wl-TeAG1 transgenic lines displayed early flowering, rosette leaf curling, and small plant size (Fig. 5a, b, c, h, l, Table 2). Furthermore, only in SlTeAG1 transgenic lines, normal sepal and petal formations were disrupted (Fig. 5d, e, f, g, Table 2). Homeotic conversion of sepal to pistil-like structure was detected at the top margin of sepals. Similar conversion of petal to stamenoid structure was observed (Fig. 5e, g, Table 2). The sepals, petals, and stamens retained at base of siliques (Fig. 5j, k). The siliques were more bumpy and smaller, and seed setting rate was lower than those of normal siliques in wild-type lines (Fig. 5, Table 2, S4).
The four whorls of floral organs from Sl-TeAG1 lines and wild-type lines were observed by $\operatorname{SEM}(i, j, k, 1.6)$. Compared with the sepals structure of wild type (Fig. 6a, b), a cluster of papilla-like cells occurred at the top of carpelloid sepals in transgenic lines (Fig. 6c), and the rough cells with stomata in normal sepals (Fig. 6a) were replaced by the smooth rectangle epidermis cells in adaxial surface of carpelloid sepals (Fig. 6d). In addition, the abaxial epidermis cells were converted from the normal rough types with stomata (Fig. 6b) into irregular smooth convex structure (Fig. 6e), which was similar to the epidermal cell structure of style (Fig. 6p). The second whorl of floral organs in the transgenic plants were converted into stamen-like petals with an anther-like structure (Fig. 6h) consisting of squamous cells (Fig. 6i). Furthermore, the epidermal cells in the lower region of the stamen-like petals were changed from a rough spindle structure (Fig. 6g) to a smooth filament-like structure (Fig. 6k, n). No obvious change was found in stamens and carpels in transgenic lines (Fig. 6l-u). In general, the overexpression of TeAG1 in Arabidopsis resulted in homeotic mutation of flower organs such as carpelloid sepals and stamen-like petals.

Since the phenotypes of ectopic expression of TeAG1 were visually focused on sepal and petal identity, the AP1, AP3, PI, AG, and STK genes in Arabidopsis were selected to detect whether their transcriptional levels were changed, based on the ABCDE model. The results (Fig. 6v, Table S7) showed that the transcript levels of $P I, A G$ and $S T K$ were significantly up-regulated in transgenic line $S l-T e A G 1$, while that of $A P 1$ was remarkably down-regulated, suggesting that ectopic expression of TeAG1 (class $\mathrm{C}$ gene) might suppress the expression levels of AP1 (class A gene) in Arabidopsis. No

Table 2 Mutant morphological traits of the transgenic plants via overexpression TeAG1 and TeAGL11-1

\begin{tabular}{|c|c|c|c|c|c|c|c|}
\hline & Rosette leaf & Flowering time & Sepal & Petal & Stamen & Pistil & Silique \\
\hline SI-TeAG1 & Less and curled rosette leaves & Early flowerin & Carpelloid sepals & Stamen-like petals & - & - & $\begin{array}{l}\text { Bumpy and small, low } \\
\text { seed setting rate }\end{array}$ \\
\hline WI-TeAG1 & Less and curled rosette leaves & Early flowerin & - & - & - & - & - \\
\hline SI-TeAGL11-1 & Less and curled rosette leaves & Early flowering & Curled petal & - & - & - & $\begin{array}{l}\text { Bumpy and small, } \\
\text { almost seedless }\end{array}$ \\
\hline WI-TeAGL11-1 & Less and curled rosette leaves & Early flowering & Curled petal & - & - & - & $\begin{array}{l}\text { Bumpy and small, low } \\
\text { seed setting rate }\end{array}$ \\
\hline
\end{tabular}



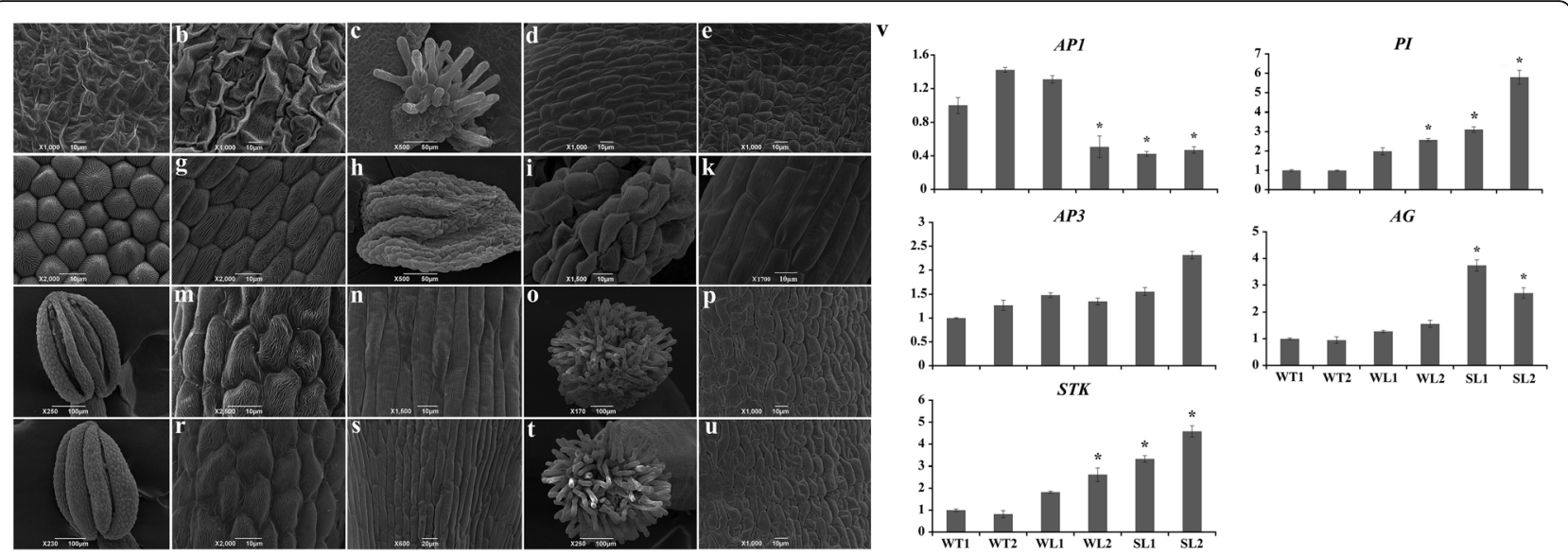

Fig. 6 Scanning electron micrograph of floral organs and expression levels of genes related to floral organ development and seed formation between TeAG1 transgenic Arabidopsis and wild-type lines. (a-u) Scanning electron micrograph of floral organs between SI-TeAG1 transgenic Arabidopsis and wildtype lines; (a, b) Adaxial (a) and abaxial (b) epidermis cells of sepals of wild-type; (c) The papilla-like cells at the top of the carpelloid sepals of transgenic plant; (d, e) Adaxial (d) and abaxial (e) epidermis cells of carpelloid sepals of transgenic plant; ( $\mathbf{f}, \mathbf{g})$ The epidermal cells at the upper $(\mathbf{f})$ and bottom portion (g) of the petals of wild-type; (h) The petals transformed into anther-like structure in transgenic lines; (i, $\mathbf{k})$ The epidermal cells at the top (i) and bottom (k) part of anther-like structure; (I) The anther structure of wild-type lines; $(\mathbf{m}, \mathbf{n})$ The epidermal cells of anther $(\mathbf{m})$ and filament $(\mathbf{n})$ in wild-type lines; (o) The papilla cells of stigma in wild-type lines; (p) the epidermal cells of style in wild-type lines; (q) The anther structure of transgenic plant; $(\mathbf{r}, \mathbf{s})$ The epidermal cells of anther (r) and filament (s) in transgenic plant; (t) The papilla cells of stigma in transgenic plant; (u) The epidermal cells of style in transgenic plant. (v) Expression levels of genes related to floral organ development and seed formation in control and transgenic Arabidopsis flowers by qRT- PCR analysis. WT1: wild-type line 1; WT2: wild-type line 2; WL1: WITeAG1 line 1; WL2: WI-TeAG1 line 2; SL1: SI-TeAG1 line 1; SL2: SI-TeAGL1 line 2. * expression level of endogenous genes in transgenic plants was 2 times higher or $1 / 2$ lower than that in wild-type plants

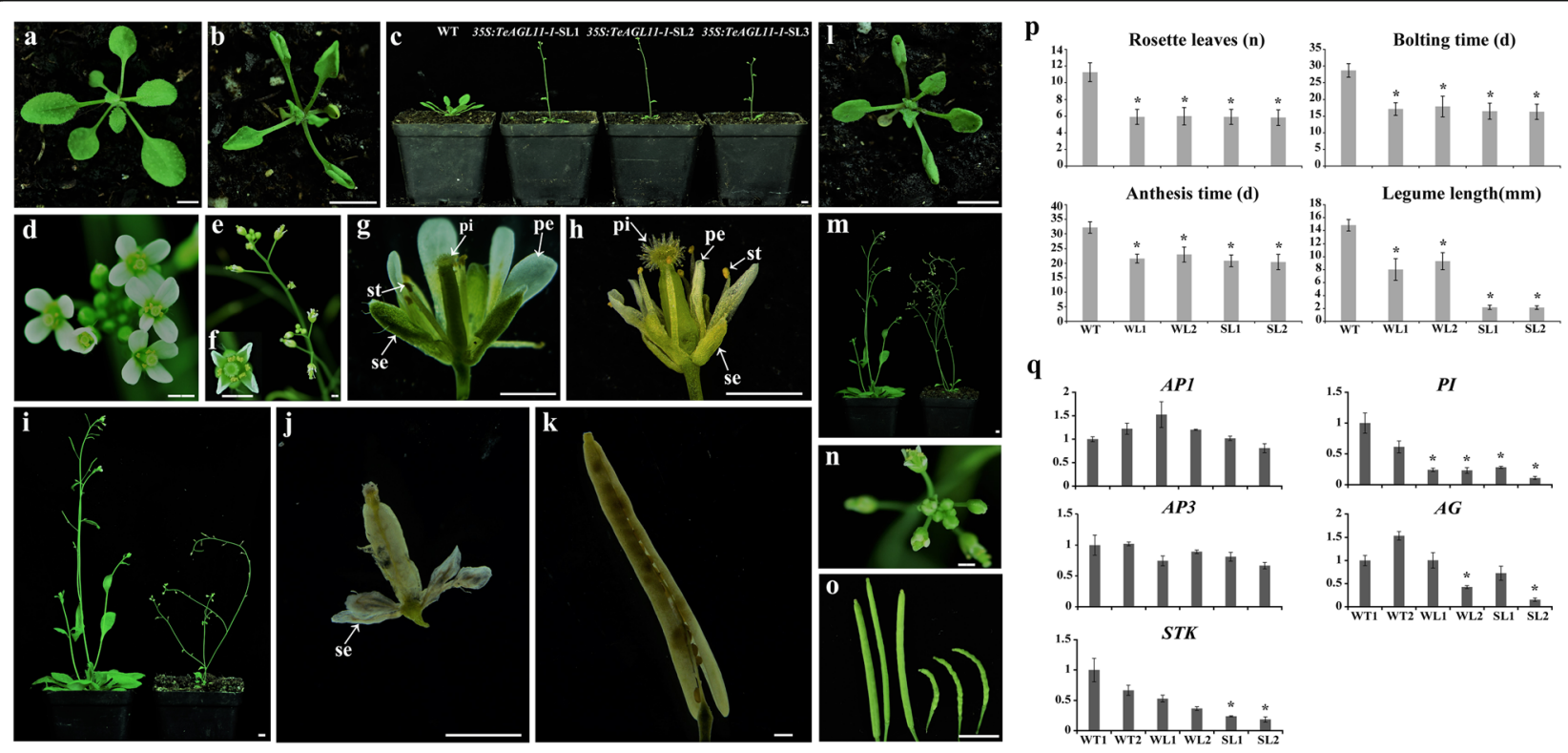

Fig. 7 Abnormal morphology of transgenic Arabidopsis plants containing 35S:TeAGL11-1 and expression levels of genes related to floral organ development and seed formation. (a) The wild-type seedling. (b, $\mathbf{c}, \mathbf{e}, \mathbf{f}, \mathbf{h}, \mathbf{i}, \mathbf{j})$ Phenotype of SI-TeAGL11-1 lines. (b) The transgenic seedlings with severely curled rosette leaves. (c) Wild-type and 35S:TeAGL11-1 transgenic plant with early flowering. (d, g) Wild-type flowers. (e, f, h) Transgenic flowers. (i) Wild-type (left) and transgenic plant (right) with smaller plants. (j, k) The siliques are almost seedless and short with unabscised sepals (j), compared to those from wild-type (k). (I-o) Phenotype of WI-TeAGL11-1 lines. (I) The transgenic seedlings with severely curled rosette leaves. (m) Wildtype (left) and transgenic plant (right) with smaller plants. (n) Transgenic flowers. (o) The smaller siliques (right). se: sepal; pe: petal; st: stamen; pi: pistil, $\mathrm{a}-\mathrm{c}, \mathrm{i}, \mathrm{l}, \mathrm{m}$. o, bar $=5 \mathrm{~mm} ; \mathrm{d}-\mathrm{h}, \mathrm{j}, \mathrm{k}, \mathrm{n}$ bar $=1 \mathrm{~mm}$. (p) Statistics for main morphological traits of the control and transgenic plants, ${ }^{*}$ significant difference at $P<0.05$. (q) Expression levels of genes related to floral organ development and seed formation in control and transgenic Arabidopsis flowers by qRT- PCR analysis. WT1: wild-type line 1; WT2: wild-type line 2; WL1: WI-TeAGL11-1 line 1; WL2: WI-TeAGL11-1 line 2; SL1: SI-TeAGL11-1 line 1; SL2: SITeAGL11-1 line 2. * expression level of endogenous genes in transgenic plants was 2 times higher or 1/2 lower than that in wild-type plants 
significant difference in the transcript level of AP3 (B class gene) was observed between wild type and $\mathrm{Sl}$ TeAG1 lines (Fig. 6v, Table S7). Compared with the results observed in Sl-AG1 line, similar change tendency and mild expression level changes of AP1, PI, AP3, AG and STK were detected in Wl-AG1 lines (Fig. 6v, Table S7).

\section{Effect of ectopic expression of TeAGL11-1 in Arabidopsis on petals and seed development}

In order to investigate the function of TeAGL11-1 and TeAGL11-2, the two genes were also ectopically expressed in Arabidopsis. We obtained twenty-one 35S: TeAGL11-1 transgenic lines with seven severe phenotype lines (Sl-TeAGL11-1), ten weak phenotype lines (Wl-TeAGL11-1), and four lines without phenotypic changes. We obtained forty-six 35S:TeAGL11-2 transgenic lines without any evident phenotypic alteration, compared with the wild-type lines. Transcript levels of TeAGL11-1 and TeAGL11-2 were further analyzed by semi-quantitative RT-PCR with flower cDNA as templates (Fig. S3c, d). The overexpression of TeAGL11-1 in Arabidopsis resulted in upward and inward curling of rosette leaves, obvious petal curling, early flowering, and small plant size (Fig. 7a, b, c, d, e, f, g, h, i, l, m, n, p, Table 2). In Sl-TeAGL11-1 lines, the siliques were almost seedless and smaller than those in wild-type lines, and the sepals were not detached from siliques (Fig. 7j, $\mathrm{k}$, p, Table 2, S5). However, in Wl-TeAGL11-1 lines, only bumpy and small siliques were observed (Fig. 7j, k, o, p, Table 2).

To explore whether the phenotype was affected by the expression of the endogenous gene AP1, PI, AP3, AG, and $S T K$ regulating the floral organs and ovule development, the qRT-PCR analysis was performed in the two severe phenotype lines, two weak phenotype lines, and two wild-type lines. As shown in Fig. 7q and Table S8, the transcript levels of $A P 1$ and $A P 3$ exhibited no significant difference among the six samples. The expression level of $P I$ was obviously down-regulated in both $\mathrm{Sl}$ TeAGL11-1and Wl-TeAGl11-1 lines, but the expression level of STK was lower in Sl-TeAGL11-1 lines than in Wl-TeAGl11-1 lines, suggesting that the seedless phenotype in $S l-T e A G L 11-1$ lines might be related to the downregulation of STK.

\section{Expression profile analysis of endogenous genes related to early flowering and curled leaves}

We also detected the expression level of endogenous genes related to flowering time (AP1, FT, LFY, SOC1, $A G$ and SEP3) and curled leaves (GRF1, GRF2, GRF5, TCP3, TCP18, TCP20, and ARF2), when the transgenic and wild-type seedlings were 10 days old. As shown in Fig. 8, the expression levels of AP1, FT, SOC1, AG and SEP3 were significantly higher in all the 35S:TeAG1 transgenic seedlings than in wild-type seedings. However, the expression level of the $L F Y$ was remarkably increased in Sl-AG1 lines, and slightly increased in $\mathrm{Wl}$ AG1 lines (Fig. 8a, Table S9). Transcripts analysis of leaf development-related genes in 35S:TeAG1 transgenic seedlings indicated that expression levels of $A R F 2$, GRF1, GRF5, TCP2O and TCP3 had no significant difference among the six samples (Fig. 8a, Table S9), whereas the expression levels of GRF2 and TCP18 were obviously higher than those in wild-type lines, suggesting that high expression of GRF2 and TCP18 might have caused the leaf curling.

In Wl-TeAGL11-1 lines and Sl-TeAGL11-1 lines, AP1, $A G, F T$ and SEP3 were strongly up-regulated. The expression levels of SOC1 were increased in Sl-TeAGL111 lines, and no significant difference in the expression level of SOC1 was observed between Wl-TeAGL11-1 lines and wild-type lines (Fig. 8b, Table S10). The results suggested that AP1, AG, FT and SEP3 might contribute

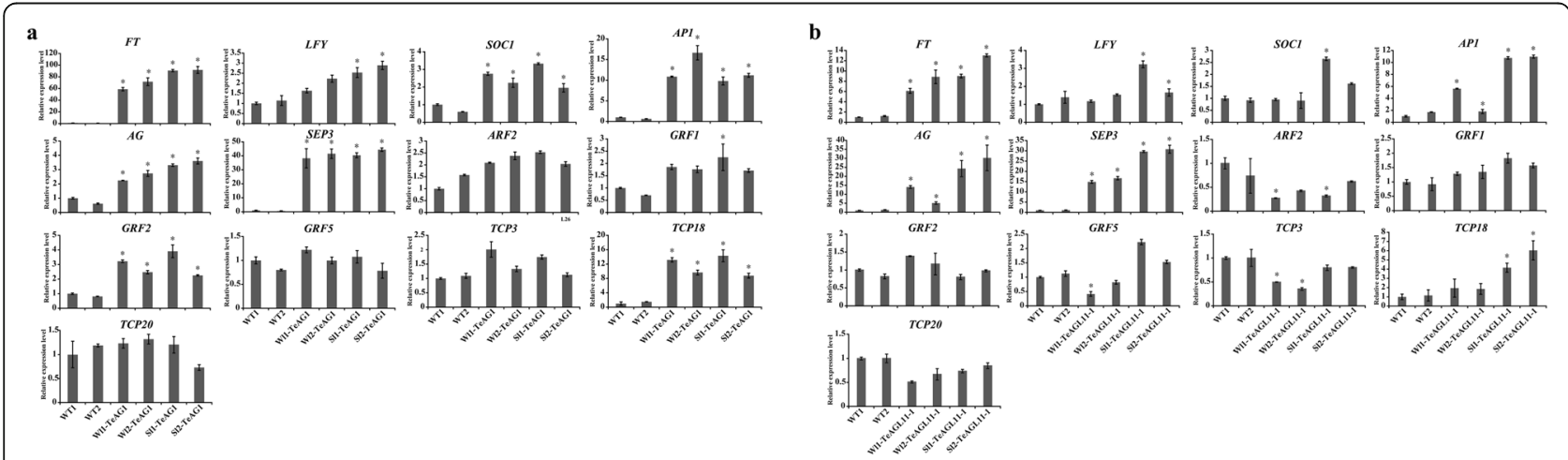

Fig. 8 qRT-PCR analysis of endogenous flowering and leaf development-related genes in 10-day-old seedlings of the wild-type, 35S:TeAG1 and 355:TeAGL11-1 transgenic lines of Arabidopsis. (a) qRT-PCR analysis of endogenous flowering and leaf development-related genes in 355:TeAG1 transgenic lines. (b) qRT-PCR analysis of endogenous flowering and leaf development-related genes in 35S:TeAGL11-1 transgenic lines. * expression level of endogenous genes in transgenic plants was 2 times higher or $1 / 2$ lower than that in wild-type plants 
to the early flowering in $35 \mathrm{~S}: T e A G 11-1$ transgenic lines. Expression levels of leaf development-related genes showed a complex expression pattern in 35S:TeAGL111 transgenic lines. The transcript level of TCP18 in SlTeAGL11-1 lines was up-regulated and obviously higher than that in wild-type lines, and slightly increased in $\mathrm{Wl}$ AG11-1 lines (Fig. 8b). ARF2 and TCP3 were downregulated in Sl-TeAGL11-1 lines, and TCP3 was significantly decreased in Wl-TeAGL11-1 lines. Expression levels of GRF1, GRF2, GRF5 and TCP2O had no significant changes, compared with those in wild type (Fig. 8b, Table S10).

\section{Discussion}

\section{Evolutionary conservation and diversity of marigold AGAMOUS-like genes}

In flowering plants, numerous MADS-box genes are important regulators for plant growth and development. The $A G$ subfamily MADS-box genes are involved in regulating floral meristem and fruit development, and specifying reproductive organ identity in many species. Previous studies demonstrated that $A G$ subfamily genes originated from several paraphyletic lineages in flowering plants, most of which probably arose from multiple whole-genome duplication events (WGDs) in flowering plants during long-term evolutionary process [9-12]. AG and AGL11 lineages might arise from the first WGDs $[10,11]$. The $A G$ lineage underwent second WGDs in lower eudicots, resulting in the generation of two subclades, namely, euAG and $P L E[9,10]$. Recently, duplication events of PLE lineages observed in Arabidopsis [23] and tomato [39] made their function different from that of euAG. In marigold, TeAG1, TeAG2, TeAGL11-1, and TeAGL11-2 were grouped into AG subfamily proteins. These four proteins contained highly conservative AG motif I and AG motif II in the C-terminal regions (Fig. 1) [10, 40]. According to our phylogenetic analysis, TeAG1 and TeAG2 belonged to euAG lineages, TeAGL11-1 and TeAGL11-2 were classified into AGL11 lineages, whereas no PLE lineage proteins were found in marigold transcriptome data (Fig. 2). Dreni and Kater's proposal suggests that PLE lineage proteins might lost in Asteraceae family, which might be related to dry, indehiscent seed in Asteraceae [9].

\section{Specific expressions of marigold AGAMOUS-like genes in inner two whorls of floral organs and ovules}

In marigold, we found that the expressions of four $A G$ subfamily genes were highly tissue-specific. The expression patterns of TeAG1 and TeAG2 (C class genes) in floral organs were consistent with those reported in Gerbera [35]. These two genes were preferentially expressed in reproductive organ and ovules (Fig. 3a, b, Fig. S1a, b), indicating that TeAG1 and TeAG2 might play an important role in regulating the reproductive organ development and specifying ovary identity. Furthermore, TeAG1 and TeAG2 were slightly expressed in sepals and petals, suggesting TeAG1 might be involved in regulating four-whorl floral organ developments. Unlike TeAG2, TeAG1 was highly expressed in pistils and ovaries, indicating their functional differentiation. Similar to TeAG1 and TeAG2 expression pattern, TeAGL11-1 and TeAGL11-2 (D class genes) were highly expressed in pistils and ovaries (Fig. 3a, b, S1a-d), suggesting that both $C$ class and D class genes in marigold might be involved in regulating pistil and ovary development in the evolutionary process. The expression patterns of TeAGL11-1 and TeAGL11-2 were clearly different from each other. TeAGL11-1 was highly expressed in disk flower organs including stamens, sepals, and ovaries, while TeAGL11-2 was highly expressed in pistils and ovules (Fig. 3a, b, S1c, d). Combining the above finding with the fact of low amino acid sequence identity between TeAGL11-1 and TeAGL11-2 proteins, we speculated that these two genes might have various functions in regulating flower development. The expression patterns of TeAGL11-1 and TeAGL11-2 differed from those of $F B P 7, F B P 11$, or $S T K$ whose expressions were limited to seed and ovule [41, 42]. Thus, the specific expression of $\mathrm{D}$ class genes in marigold suggested some extra functions of TeAGL11-1 or TeAGL11-2 in addition to regulating seed development.

\section{Conservative role of TeAG1 in specifying stamen and carpel identities}

Compared to previous studies in other plants, the similar phenotypic changes of flower organs and seed development were observed in 35S:TeAG1 transgenic lines. The ectopic expression of TeAG1 in Arabidopsis resulted in homeotic conversion of sepals into pistilliod structures and that of petals into stamenoid structures (Figs. 5e, g, 6e, f, h, l, Table 2), which was consistent with the results of ectopic expression of $\mathrm{C}$ class genes in Chrysanthemum [43] and Carnation (Dianthus caryphyllus) [44]. For example, ectopic expression of CDM37 (C class gene) in Chrysanthemum resulted in the conversion of petals into antheroid structure, and that of sepals into pistilloid tissues [43]. Based on ABCDE model, ectopic expression of functional class $C$ orthologue would suppress the A class homeotic genes expression in the first and second whorls, leading to the transformation of sepals and petals into carpels and stamens, respectively. The analysis of the expression pattern of endogenous genes AP1, AP3, PI, AG, and STK revealed that TeAG1 developed activities to repress A class genes (Fig. 6v). Based on the specific expression of TeAG1 and the noticeable phenotypic alteration of transgenic plants, we 
speculated that TeAG1 might regulate the stamen and carpel developments.

\section{Function of TeAGL11-1 in seed and petal development} The phenotypical changes caused by TeAGL11-1 overexpression in Arabidopsis suggested that D class genes might have conservative and divergent function. The almost seedless phenotype in 35S:TeAGL11-1 lines was similar to that in other plant species in which D class gene expression were suppressed, suggesting that the function of class D genes in transgenic Arabidopsis is partially inhibited. In Arabidopsis, the triple stk/shp1/ shp2 abolished the development of ovule and seed [24]. In Petunia, simultaneous down-regulation of FBP7 and $B P 11$ formed the seedless phenotype $[18,20,41]$. In addition to model plants, similar phenotypes resulting from down-regulation the $\mathrm{D}$ class genes were also observed in other species $[2,3]$. The down-regulation expression of endogenous gene STK also supported this phenotypic change (Fig. 7q), suggesting that ectopic expression TeAGL11-1 in Arabidopsis led to cosuppression phenotype. Co-suppression phenomenon was observed in other ectopic expression lines of MADS-box genes. For example, overexpression HAM45as and HAM59 (C class) genes from Sunflower in tobacco downregulated the expression level of endogenous $C$ class genes, further resulting in the conversion of stamen into petals [45]. In addition, the curled petals in 35S:TeAGL11-1 lines were observed, but this phenotype was different from those resulting from overexpression of D class genes in Arabidopsis and tomato where the sepals were transformed into carpeloid organs bearing ovules [42] or a fleshy organ [3]. On one hand, the different phenotypes might be attributed to the functional difference between TeAGL11-1 and STK (Arabidopsis) or Sl-AGL11(tomato, Solanum lycopersicum). On the other hand, different gene regulatory networks in marigold and Arabidopsis might lead to their difference in heterologous transformation phenotype. The decrease in PI transcript level might explain the petal curling (Fig. $7 \mathrm{q})$.

\section{Functional conservation and diversity of TeAG1 and TeAGL11-1 genes}

The early flowering phenotype was observed in transgenic plants containing 35S:TeAG1 and 35S:TeAGL11-1 constructs (Figs. 5c, l, 7c, p, Table 2), which was consistent to the phenotype of transgenic Arabidopsis with the overexpression of $A G$ or $S T K[42,46]$. In addition, overexpression TeAG1 and TeAGL11-1 in Arabidopsis led to rosette leaf curling (Figs. 5b, 7b, l, Table 2). Similar phenotype was also observed in transgenic plants in which $\mathrm{C}$ or D class genes were ectopically expressed [47, 48]. Remarkably, in Arabidopsis, ectopic expressions of
TeAG1 and TeAGL11-1 resulted in short siliques, low seed setting rate, and sepal retainment at the bottom of mature siliques. This result was consistent with the finding reported in Cymbidium [49]. The expression analysis of endogenous gene STK suggested that short siliques with low seed setting rate might be correlated with the increased STK expression level in 35S:TeAG1 lines, while the short siliques with low seed setting rate might be associated with the decreased STK transcript level in TeAGL11-1 transgenic lines. In general, these results supported our prediction that ectopic expression of $\mathrm{C}$ and D class genes might have similar functions in regulating the floral development in Arabidopsis [50]. In addition, the divergent function between TeAG1 and TeAGL11-1 were also observed. Compared with phenotypic changes of 35S:TeAG1 transgenic plants, the overexpression of TeAGL11-1 caused the petals to curl inwards, but it could not induce homologous alteration of floral organs (Fig. 7e, f, h, n, Table 2).

Previous studies indicated that the early flowering and curled leaves caused by overexpression of MADS-box genes might be usually associated with expression changes of upstream or downstream genes [51-54]. In this study, the transcript levels of endogenous genes regulating flowering time and curled leaves in 35S: TeAG1, 35S:TeAGL11-1 lines and wild-type plants were analyzed. The results indicated that the transcript levels of $A P 1, F T, A G$, and SEP3 were up-regulated in 35S: TeAG1 and 35S:TeAGL11-1 lines. Previous report on soybean (Glycine max) indicated that the early flowering was related to the up-regulated transcript levels of $A P 1$, $F T$, and SEP3 [55]. Taken together, the increased expression levels of $A P 1, F T, A G$, and SEP3 might promote the formation of flowers and early flowering in transgenic plants (Fig. 8a, b). The analysis of gene expression and phenotypic changes revealed that the leaf curling in 35S: TeAG1 transgenic lines might be correlated with the transcript changes of GRF2 and TCP18 (Fig. 8a), which was consistent with results that TCP [56] and GRF [57] could regulate leaf development. In addition, the downregulation of $A R F 2$ and TCP3 and up-regulation of TCP18 might result in the curled leaves in 355 : TeAGL11-1 lines (Fig. 8b). The expression of $L F Y$ was evidently increased in transgenic lines with higher expression level of TeAG1, suggesting the expression levels of $L F Y$ might be related to the transgene expression.

\section{Conclusions}

This study reveals that TeAG1 and TeAGL11-1 regulate the development of floral organs, seeds and vegetative tissues, and that TeAG2 and TeAGL11-2 might lose their ability to regulate the floral organ and ovules developments, or they need bind with other MADS-box genes to regulate the flower development and ovules 
formation. Our results expand the understanding of the development of stamens, pistils and ovules in Asteraceae family, and provide technical support for the subsequent creation of horticultural traits. However, further situ hybridization analysis and homologous transformation phenotyping experiments are still needed to explore the accurate expression regions and potential functional mechanism of these four genes.

\section{Methods}

\section{Plant materials and growth conditions}

An inbred line M525B-1 of marigold was derived from 10 generations of continuous self-crossing of M525B which is a male fertile type plant from the two-type (male sterile/male fertile) line M525AB isolated by $\mathrm{He}$ [58] in our lab. M525B-1 had one whorl of ray florets in the periphery of the capitulum. They were grown in the natural conditions in fall 2016 at Huazhong Agricultural University, Wuhan, Hubei Province, China (lat. $30^{\circ} 28^{\prime}$ $36.5^{\prime \prime} \mathrm{N}$, long, 114²1’59.4” E).

The seeds from Arabidopsis thaliana accession Columbia (Col-0) plants used for the functional analysis were first sterilized and cultured on the agar containing Skoog (MS) and $1 / 2 \times$ Murashige at $4{ }^{\circ} \mathrm{C}$ for 2 days. After 10 days, the seedlings were transplanted to growth chamber under long-day conditions ( $16 \mathrm{~h}$ light/ $8 \mathrm{~h}$ dark) at $22 / 20{ }^{\circ} \mathrm{C}$ day/night temperature with $60 \%$ relative humidity until genetic transformation.

\section{Total RNA extraction, isolation and bioinformatics analysis of $A G$ and $A G L 11$ genes from marigold}

Various vegetative tissues, floral buds in four developmental stages, and floral tissues from marigold were collected and quickly frozen in liquid nitrogen as described by Ai et al. [33]. There were four different sizes of flower buds: FB1: $0-1 \mathrm{~mm}$ in diameter, the ray floret primordium and the outermost disk floret primordium were formed; FB2: $2-3 \mathrm{~mm}$ in diameter, the sepals and petals of the ray florets and the outmost disk florets were developed; FB3: $4-5 \mathrm{~mm}$ in diameter, the stamens of the outmost disk florets were developed; and FB4: 6-7 mm in diameter, the pistils of the ray florets and the outmost disk florets were developed. Total RNA of each sample was isolated by PLANTpure kit (Aidlab, Beijing, China) according to the manufacturer's protocol. The quality and quantity of RNA were tested by a Nano-Drop 2000 Spectrophotometer (Thermo Fisher Scientific, Wilmington, DE). The first-strand cDNA was synthesized by using PrimeScriptTM RT reagent Kit with gDNA Eraser (Takara, Dalian, China). Based on the transcriptome sequence (accession number SRP066084) [33], four $A G$ subfamily genes were selected and named TeAG1 (comp38613_c0, comp38613_c1), TeAG2 (comp68705_ c0), TeAGL11-1 (comp199520_c0), and AGL11-2 (comp50841_c0). The full length of TeAG1, TeAG2, TeAGL11-1, TeAGL11-2 were cloned with the specific primers TeAG1-Full-F/R, TeAG2-Full-F/R, TeAGL11-1Full-F/R, and TeAGL11-2-Full-F/R, respectively (Supplementary Table S1). The PCR amplified products were purified and cloned into $p M D 18-T$ vector (Takara, Dalian, China). Positive clones (3-5 replicates) were confirmed by sequencing in the Sangon company in Shanghai.

Multiple sequence alignment of TeAG1, TeAG2, TeAGL11-1, TeAGL11-2 proteins with other known C/ $\mathrm{D}$ class genes was performed by using the DNAMAN (v.6.0) software (https://www.lynnon.com). To analyze the phylogenetic relationships of $\mathrm{C} / \mathrm{D}$ class genes, a number of $A G$ and $A G L 11$ genes were downloaded from the National Center for Biotechnology Information (NCBI) (http://www.ncbi.nlm.nih.gov). Full-length amino-acid sequences were first aligned using the default settings in MUSCLE implemented in MEGA ( $\mathrm{v}$. 6.0 ), and then adjusted manually with the reference alignment provided by Zahn et al. [59]. Phylogenetic tree was constructed by MEGA (v. 6.0) software by using the neighbor-joining (NJ) method under 1000 bootstrap replicates.

\section{Quantitative real-time PCR for expression analysis}

Expression levels of the $C / D$ class genes in different tissues (roots, tender stems, and fresh leaves), floral tissues (sepals, petals, and pistils of ray and disk florets, stamens of disk florets, receptacles, bracts, and ovaries), and different sizes of flower buds in marigold were analyzed by quantitative real-time PCR (qRT-PCR). Gene-specific primers (Supplementary Table S1) for qRT-PCR were designed within the non-conservative $\mathrm{C}$-terminal region by the Primer Premier 5.0. QRT-PCR experiments were performed, as described in previous study [33]. The expression levels of these four genes per sample were repeated three times. In these experiments, the reference gene beta-actin was used for normalization and the relative expression levels were calculated using the $2^{-\Delta \Delta \mathrm{Ct}}$ method. The data were analyzed using the TBtools software and normalized using row scale.

\section{Subcelluar localization of AG and AGL11 proteins from marigold}

The coding sequences of TeAG1, TeAG2, TeAGL11-1, TeAGL11-2 with removed stop codon were amplified and introduced into a pYellow vector under the control of the $35 \mathrm{~S} C \mathrm{CMV}$ promoter to generate fusion vectors 35S:YFP-TeAG1, 35S:YFP-TeAG2, 35S:YFP-TeAGL11-1, 35S:YFP-TeAGL11-2. The primers were listed in supplementary Table S1. The YFP signal could be observed in both cytoplasm and nucleus when transfected with 35S: YFP vector. The 35S:YFP empty vector was used as a 
negative control, and the 35S:RFP-N7 vector including the N7 nuclear targeting signal was used as a nucleus control. The control vectors and recombinant vectors were transformed into agrobacterium tumefacien strain GV3101, respectively. Then, the recombinant vectors and the nucleus control 35S:RFP-N7 or the pYellow-YFP empty and nucleus control 35S:RFP-N7 in tumefacien strain GV3101 were simultaneously injected into tobacco (Nicotiana benthamiana) leaves, separately [60]. After incubation at $25^{\circ} \mathrm{C}$ for $48 \mathrm{~h}$, the YFP fluorescence signal and RED fluorescence signal in tobacco leaves were detected by confocal microscopy (Leica, TCS SP2, Wetzlar, Germany).

\section{Yeast two-hybrid assay}

The cDNA of TeAG1, TeAG2, TeAGL11-1, and TeAGL11-2 were amplified using primers with specific restriction sites (Table S1). The PCR fragments were recombined with the plasmid pGBKT7 and pGADT7 (Clontech, Palo Alto, CA, USA), respectively. The PGAD T7 and PGBKT7 recombinant vectors were cotransformed into strain $A H 109$ by the LiAc/DNA/PEG method following the the Frozen-EZ Yeast Transformation II Kit protocols (Zymo Research Corp, Irvine, CA, USA). The transformants were selected on selection medium lacking leucine (Leu) and tryptophan (Trp). The autoactivation and toxicity of BD clones were tested by co-transforming with empty AD plasmid. Simultaneous transfer of empty $\mathrm{AD}$ and empty $\mathrm{BD}$ vectors or pGBKT7-53 and pGADT7-T vectors into AH109 was set as the negative control or positive control. The positive yeast cells were verified by PCR with AD-F-/R and BD-F-/R (Supplementary Table S1). Then positive yeast cells were further tested by spotting assays on $\mathrm{X}$-a-galsupplemented medium without Leu, Trp, histidine (His), and adenine (Ade). The result was observed after incubation of plates at $30^{\circ} \mathrm{C}$ for $3-5$ days. In this study, the positive signal of interaction ability was scored if any direction interaction caused yeast to grow on the selection plate.

\section{Vectors construction and ectopic expression in \\ Arabidopsis}

The coding regions of TeAG1, TeAG2, TeAGL11-1 and TeAGL11-2 were amplified using specific primers with restriction sites (Supplementary Table S1), and then were cloned into $p 2300$ vector under the control of the CaMV $35 S$ promoter. The obtained fusion vectors were named 35S:TeAG1, 35S:TeAG2, 35S:TeAGL11-1, and 35S:TeAGL11-2. These fusion vectors were introduced into Escherichia coli DH5a, and tested by PCR. These fusion vectors were then transformed into Agrobacterium tumefaciens strain GV3101. These resultant constructs were transformed into wild-type Arabidopsis ecotype
Columbia plants by using the floral dip method [61] Transformants were selected on a medium containing $50 \mu \mathrm{g} \mathrm{ml}^{-1}$ kanamycin, and were further verified by PCR and semi-quantitative RT-PCR (semi-RT-PCR) analysis with the primers 35S-F, 35S-TeAG1-R, 35S-TeAG2-R, 35S-TeAGL11-1-R, 35S-TeAGL11-2-R, qRT-TeAG1-F/ R, qRT-TeAG2-F/R, RT-TeAG11-1-F/R, RT-TeAGL112-F/R, and AtEF1 $\alpha-\mathrm{F} / \mathrm{R}$ (Supplementary Table S1). Phenotype changes of $\mathrm{T} 1$ and $\mathrm{T} 2$ transgenic lines were analyzed.

\section{Scanning electron microscopy}

The blooming flowers of 35S:TeAG1 and wild-type plants were collected and fixed overnight in $2.5 \%(\mathrm{v} / \mathrm{v})$ glutaraldehyde at $4{ }^{\circ} \mathrm{C}$. Then the flowers were dehydrated every $15 \mathrm{~min}$ with an ethanol series $(30-100 \%)$. Ethanol was replaced with isoamyl acetate/ethanol (1/1) and isoamyl acetate for every $10 \mathrm{~min}$. The dried samples were critical point dried (CPD 020; Balzers Union, http://www.bal-tec. com/), sputter-coated with gold (NanotechSEMPrep II sputtercoater, NanotechLtd, Prestwick, UK), and fixed on the specimen stubs by double-sided tape. The samples were examined and photographed using a LEO 435VP scanning electron microscope (LEO Electron Microscopy Ltd., http://www. smt.zeiss.com/).

\section{Expression analysis of endogenous genes in transgenic plants}

To further analyze the mechanism of floral organs and seed phenotype changes in 35S:TeAG1 and 35S: TeAGL11-1 transgenic plants, the expression levels of $A P 1, A P 3, P I, A G$ and $A G L 11$ of Arabidopsis were detected by qRT-PCR. Total RNA of blooming flowers from 35S:TeAG1, 35S:TeAGL11-1 transgenic plants and wild-type plants was isolated by using PLANTpure (Aidlab, Beijing, China), and then reverse-transcribed by using PrimeScript ${ }^{\mathrm{Tm}}$ RT reagent Kit with gDNA Eraser

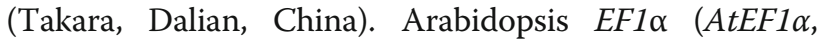
AT5G60390) was used as housekeeping gene. In addition, the transcript levels of some endogenous genes related to flowering time (FT, SOC1, LFY, AP1, SEP3, $A G)$ [54] and leaf development (GRF1, GRF2, GRF5, TCP3, TCP18, TCP20, and ARF2) were analyzed [62], when the transgenic and wild-type seedlings were 10 days old. All the samples of 10-day-old seedlings were collected at the same time under light conditions. The primers were listed in Supplementary Table S1.

\section{Supplementary information}

Supplementary information accompanies this paper at https://doi.org/10. 1186/s12870-020-02644-5.

Additional file 1: Table S1. Sequence of primers 
Additional file 2: Table S2. Amino acid sequence alignment of $C$ class proteins.

Additional file 3: Table S3. Amino acid sequence alignment of D class proteins.

Additional file 4: Fig. S1. Expression levels of TeAG1, TeAG2, TeAGL11-1 and TeAGL11-2 in different tissues and organs. Rt: root; Sm: stems; Le: leaf; FB1-FB4: flower buds were 0-1 mm, 2-3 mm, 4-5 $\mathrm{mm}$ and 6-7 $\mathrm{mm}$ in diameter, respectively; Re: receptacle; Br: bract; RS: sepal of ray floret; RP: petal of ray floret; RPi: pistil of ray floret; Se: sepal of disk floret; Pe: petal of disk floret; St: stamen of disk floret; Pi: pistil of disk floret; Ov: ovary.

Additional file 5: Fig. S2. Interactions of TeAG and TeAGL11 proteins of marigold by yeast two-hybrid assays. (a) Assession of Self-activation and autoaction of $\mathrm{AD}$ and $\mathrm{BD}$ constructs. (b)Ten-fold serial dilutions from $10^{-1}$ to $10^{-4}$ of each culture were spotted on the selected SD -Leu/ -Trp/-His/-Ade plates with X-a-gal.

Additional file 6: Fig. S3. Expression of TeAG1, TeAG2, TeAGL11-1 and TeAGL11-2 in seedlings of T1 transgenic lines by semi-quantitative RTPCR. (a-1) 35S:TeAG1 transgenic lines. (b-1) 35S:TeAG2 transgenic lines. (c1) 35S:TeAG11-1 transgenic lines. (d-1) 35S:TeAG11-2 transgenic lines. WT: wild type line; SL: strong phenotypic line; WL: weak phenotypic line; L: transgenic line. $(a-2, b-2, c-2, d-2)$, the constitutive gene is Arabidopsis keeping-house gene AtEF1a. (DOCX 654 kb)

Additional file 7: Table S4. Statistics for seed setting rate between control and SI-TeAG1 transgenic lines.

Additional file 8: Table S5. Statistics for seed setting rate between control and SI-TeAGL11-1 transgenic lines.

Additional file 9: Table S6. Raw data of $C_{T}$ value in qRT-PCR for expression levels of TeAG1, TeAG2, TeAGL11-1, and TeAGL11-2 in different tissues and organs of marigold.

Additional file 10: Table S7. Raw data of $C_{T}$ value in qRT-PCR for expression levels of AP1, AP3, PI, AG, and STK in flowers from 35S:TeAG1 transgenic lines and wild-type Arabidopsis.

Additional file 11: Table S8. Raw data of $C_{T}$ value in qRT-PCR for expression levels of AP1, AP3, PI, AG, and STK in flowers from 35S:TeAGL11-1 transgenic lines and wild-type Arabidopsis.

Additional file 12: Table S9. Raw data of $C_{T}$ value in qRT-PCR for expression levels of AP1, AP3, PI, AG, and STK in seedlings of 35S:TeAG1 transgenic lines and wild-type Arabidopsis.

Additional file 13: Table S10. Raw data of $C_{T}$ value in $q R T-P C R$ for expression levels of AP1, AP3, PI, AG, and STK in seedlings of 35S:TeAGL11-1 transgenic lines and wild-type Arabidopsis.

\section{Abbreviations}

AP1: APETALA1; AP3: APETALA1; SEP3: SEPALLATA3; PI: PISTILLATA;

TCP: TEOSINTEBRANCHED 1, CYCLOIDEA, PROLIFERATING FACTOR;

GRF: GROWTH-REGULATING FACTOR; ARF2: AUXIN RESPONSE REGULATOR 2;

FT: FLOWERING LOCUS T; SOC1: SUPPRESSOR OF OVEREXPRESSION CO 1;

LFY: LEAFY; AG: AGAMOUS; WGDs: whole-genome duplication events;

AGAL 11: AGAMOUS-LIKE11; PLE: PLENA; FBP7: FLORAL BINDING PROTEIN 7;

FBP11: FLORAL BINDING PROTEIN 11; STK: SEEDSTICK; SHP1: SHATTERP

ROOT1; SHP2: SHATTERPROOT1; YFP: yellow fluorescent protein; RFP: red

fluorescent protein; Leu: leucine; Trp: tryptophan; His: histidine; Ade: adenine;

RT-qPCR: quantiative real-time PCR; Semi-PCR: semi-quantitative-PCR

\section{Acknowledgments}

The authors are grateful to all past and present colleagues in our lab for constructive discussion and technical support.

\section{Authors' contributions}

Conceived and designed the experiments: YHH, CLZ. Performed the experiments: CLZ. Analyzed the data: CLZ, YQW. Contributed reagents/ materials/analysis tools: CLZ, LDW, WJW, WQQ, HL, ZC. Wrote the paper: CLZ, $\mathrm{YHH}, \mathrm{ZC}$, WQQ, MZB. All authors read and approved the final manuscript.

\section{Funding}

This research was supported by grants from National Natural Science Foundation of China (31672181) and the Fundamental Research Funds for the Central Universities (2662019PY072). The funder had no role in study design, data collection and analysis, decision to publish, or preparation of the manuscript.

\section{Availability of data and materials}

The sequences information of AGAMOUS-like proteins was uploaded to the NCBI (TeAG1: MT452648, TeAG2: MT452649, TeAGL11-1: MT394168, and TeAGL11-2, MT394169).

\section{Ethics approval and consent to participate}

Not applicable.

\section{Consent for publication}

Not applicable.

\section{Competing interests}

The authors declare that they have no conflict of interests.

\section{Author details}

${ }^{1}$ Key Laboratory of Horticultural Plant Biology, Ministry of Education; College of Horticulture and Forestry Sciences, Huazhong Agricultural University, Shizishan Street No. 1, Wuhan 430070, China. ${ }^{2}$ Crop Development Centre/ Department of Plant Sciences, University of Saskatchewan, S7N5A8, Saskatoon, Canada.

Received: 16 June 2020 Accepted: 9 September 2020 Published online: 23 September 2020

\section{References}

1. Theißen G, Melzer R, Rümpler F. MADS-domain transcription factors and the floral quartet model of flower development: linking plant development and evolution. Development. 2016;143(18):3259-71..

2. Lu H, Klocko AL, Brunner AM, Ma C, Magnuson AC, Howe GT, An X, Strauss SH. RNA interference suppression of AGAMOUS and SEEDSTICK alters floral organ identity and impairs floral organ determinacy, ovule differentiation, and seed-hair development in Populus. New Phytol. 2019;222(2):923-37.

3. Huang B, Routaboul J-M, Liu M, Deng W, Maza E, Mila I, Hu G, Zouine M, Frasse P, Vrebalov JT. Overexpression of the class D MADS-box gene SIAGL11 impacts fleshy tissue differentiation and structure in tomato fruits. J Exp Bot. 2017;68(17):4869-84

4. Zhang J, Wang Y, Naeem M, Zhu M, Li J, Yu X, Hu Z, Chen G. An AGAMOUS MADS-box protein, SIMBP3, regulates the speed of placenta liquefaction and controls seed formation in tomato. J Exp Bot. 2018;70(3):909-24.

5. Rosin FM, Hart JK, Van Onckelen H, Hannapel DJ. Suppression of a vegetative MADS box gene of potato activates axillary meristem development. Plant Physiol. 2003:131(4):1613-22.

6. Alvarezbuylla ER, Garciaponce B, Sanchez MDLP, Espinosasoto C, Garciagomez ML, Pineyronelson A, Garayarroyo A. MADS-box genes underground becoming mainstream: plant root developmental mechanisms. New Phytol. 2019;223(3):1143-58.

7. Theißen G. Development of floral organ identity: stories from the MADS house. Curr Opin Plant Biol. 2001;4(1):75-85.

8. Theissen G, Saedler H. Plant biology: floral quartets. Nature. 2001;409(6819):469.

9. Dreni L, Kater MM. MADS reloaded: evolution of the AGAMOUS subfamily genes. New Phytol. 2014;201(3):717-32.

10. Kramer EM, Jaramillo MA, Di Stilio VS. Patterns of gene duplication and functional evolution during the diversification of the AGAMOUS subfamily of MADS box genes in angiosperms. Genetics. 2004;166(2):1011-23.

11. Zahn LM, Leebens-Mack JH, Arrington JM, Hu Y, Landherr LL, DePamphilis CW, Becker A, Theissen G, Ma H. Conservation and divergence in the AGAMOUS subfamily of MADS-box genes: evidence of independent suband neofunctionalization events. Evol Dev. 2006;8(1):30-45

12. Almeida AMR, Yockteng R, Otoni WC, Specht CD. Positive selection on the $K$ domain of the AGAMOUS protein in the Zingiberales suggests a mechanism for the evolution of androecial morphology. EvoDevo. 2015;6(1):7

13. Coen ES, Meyerowitz EM. The war of the whorls: genetic interactions controlling flower development. Nature. 1991;353(6339):31.

14. Bowman JL, Smyth DR, Meyerowitz EM. Genes directing flower development in Arabidopsis. Plant Cell. 1989;1(1):37-52. 
15. Yanofsky MF, Ma H, Bowman JL, Drews GN, Feldmann KA, Meyerowitz EM. The protein encoded by the Arabidopsis homeotic gene agamous resembles transcription factors. Nature. 1990;346(6279):35.

16. Drews GN, Bowman JL, Meyerowitz EM. Negative regulation of the Arabidopsis homeotic gene AGAMOUS by the APETALA2 product. Cell. 1991;65(6):991-1002.

17. Aida R, Komano M, Saito M, Nakase K, Murai K. Chrysanthemum flower shape modification by suppression of chrysanthemum-AGAMOUS gene. Plant Biotechnol. 2008;25(1):55-9.

18. Heijmans K, Ament K, Rijpkema AS, Zethof J, Wolters-Arts M, Gerats T, Vandenbussche M. Redefining C and D in the petunia ABC. Plant Cell. 2012; 24(6):2305-17.

19. Yamaguchi T, Lee DY, Miyao A, Hirochika H, An G, Hirano H-Y. Functional diversification of the two C-class MADS box genes OSMADS3 and OSMADS58 in Oryza sativa. Plant Cell. 2006;18(1):15-28.

20. Angenent GC, Franken J, Busscher M, van Dijken A, van Went JL, Dons $H$, van Tunen AJ. A novel class of MADS box genes is involved in ovule development in petunia. Plant Cell. 1995;7(10):1569-82.

21. Colombo L, Franken J, Koetje E, van Went J, Dons H, Angenent GC, van Tunen AJ. The petunia MADS box gene FBP11 determines ovule identity. Plant Cell. 1995;7(11):1859-68.

22. Ma H, Yanofsky MF, Meyerowitz EM. AGL1-AGL6, an Arabidopsis gene family with similarity to floral homeotic and transcription factor genes. Genes Dev. 1991;5(3):484-95.

23. Liljegren SJ, Ditta GS, Eshed Y, Savidge B, Bowman JL, Yanofsky MF. SHATTE RPROOF MADS-box genes control seed dispersal in Arabidopsis. Nature. 2000;404(6779):766.

24. Pinyopich A, Ditta GS, Savidge B, Liljegren SJ, Baumann E, Wisman E, Yanofsky MF. Assessing the redundancy of MADS-box genes during carpel and ovule development. Nature. 2003;424(6944):85.

25. Brambilla V, Battaglia R, Colombo M, Masiero S, Bencivenga S, Kater MM, Colombo L. Genetic and molecular interactions between BELL1 and MADS box factors support ovule development in Arabidopsis. Plant Cell. 2007; 19(8):2544-56.

26. Battaglia R, Brambilla V, Colombo L. Morphological analysis of female gametophyte development in the bel1 stk shp1 shp2 mutant. Plant Biosystems-An International Journal Dealing with all Aspects of Plant Biology. 2008;142(3):643-9.

27. Mizzotti C, Mendes MA, Caporali E, Schnittger A, Kater MM, Battaglia R, Colombo L. The MADS box genes SEEDSTICK and ARABIDOPSIS Bsister play a maternal role in fertilization and seed development. Plant J. 2012;70(3): 409-20.

28. Ocarez N, Mejía N. Suppression of the D-class MADS-box AGL11 gene triggers seedlessness in fleshy fruits. Plant Cell Rep. 2016;35(1):239-54.

29. Broholm SK, Teeri TH, Elomaa P. Molecular control of inflorescence development in Asteraceae. Adv Bot Res. 2014;72:297-333.

30. Chen J, Shen C, Guo Y, Rao G. Patterning the Asteraceae Capitulum: Duplications and Differential Expression of the Flower Symmetry CYC2-Like Genes. Front Plant Sci. 2018:9:551.

31. Zoulias N, Duttke SH, Garces H, Spencer V, Kim M. The role of auxin in the pattern formation of the Asteraceae flower head (capitulum). Plant Physiol. 2019;179(2):391-401.

32. Githeng'u SK, Ding L, Zhao K, Zhao W, Chen S, Jiang J, Chen F. Ectopic expression of Chrysanthemum CDM19 in Arabidopsis reveals a novel function in carpel development. Electron J Biotechnol. 2020;45(2):10-8.

33. Ai Y, Zhang C, Sun Y, Wang W, He Y, Bao M. Characterization and Functional Analysis of Five MADS-Box B Class Genes Related to Floral Organ Identification in Tagetes erecta. PLoS One. 2017;12(1):e0169777.

34. Broholm SK, Pollanen E, Ruokolainen S, Tahtiharju S, Kotilainen M, Albert VA, Elomaa P, Teeri TH. Functional characterization of B class MADS-box transcription factors in Gerbera hybrida. J Exp Bot. 2010;61(1):75-85.

35. Yu D, Kotilainen M, Pöllänen E, Mehto M, Elomaa P, Helariutta Y, Albert VA, Teeri TH. Organ identity genes and modified patterns of flower development in Gerbera hybrida (Asteraceae). Plant J. 1999;17(1):51-62.

36. Shchennikova AV, Shulga OA, Sizeneva ES, Perkovskaya NI, Skryabin KG. Diversification of functional activity of the chrysanthemum homeotic MADS -box gene CDM37. Dokl Biochem Biophys. 2011;436(1):29-31.

37. Shulga O, Mitiouchkina T, Shchennikova A, Skryabin K, Dolgov S. Chrysanthemum modification via ectopic expression of sunflower MADSbox gene HAM59. In: XXV International EUCARPIA Symposium Section Ornamentals: Crossing Borders 1087; 2015. p. 105-11.
38. Mandel JR, Dikow RB, Siniscalchi CM, Thapa R, Watson LE, Funk VA. A fully resolved backbone phylogeny reveals numerous dispersals and explosive diversifications throughout the history of Asteraceae. Proc Natl Acad Sci U S A. 2019;116(28):14083-8.

39. Garceau DC, Batson MK, Pan IL. Variations on a theme in fruit development: the PLE lineage of MADS-box genes in tomato (TAGL1) and other species. Planta. 2017;246(2):313-21.

40. Yun P-Y, Kim S-Y, Ochiai T, Fukuda T, Ito T, Kanno A, Kameya T. AVAG2 is a putative D-class gene from an ornamental asparagus. Sex Plant Reprod. 2004;17(3):107-16.

41. Colombo L, Franken J, Van der Krol AR, Wittich PE, Dons H, Angenent GC. Downregulation of ovule-specific MADS box genes from petunia results in maternally controlled defects in seed development. Plant Cell. 1997;9(5): 703-15.

42. Favaro R, Pinyopich A, Battaglia R, Kooiker M, Borghi L, Ditta G, Yanofsky MF, Kater MM, Colombo L. MADS-box protein complexes control carpel and ovule development in Arabidopsis. Plant Cell. 2003;15(11):2603-11.

43. Shchennikova AV, Shul'ga OA, Sizeneva ES, Perkovskaya NI, Skryabin KG. Diversification of functional activity of the Chrysanthemum homeotic MADS-box gene CDM37. Dokl Biochem Biophys. 2011;436(1):29-31.

44. Wang Q, Dan N, Zhang X, Lin S, Bao M, Fu X. Identification, Characterization and Functional Analysis of C-Class Genes Associated with Double Flower Trait in Carnation (Dianthus caryphyllus L.). Plants. 2020;9(1):87.

45. Sizeneva ES, Shulga OA, Shchennikova AV, Skryabin KG. Functional diversification of two MADS-Box genes, HAM45 and HAM59, in sunflower. Dokl Biol Sci. 2013;451(1):221-4.

46. Mizukami Y, Ma H. Determination of Arabidopsis floral meristem identity by AGAMOUS. Plant Cell. 1997:9(3):393-408.

47. Hsu H-F, Hsieh W-P, Chen M-K, Chang Y-Y, Yang C-H. C/D class MADS box genes from two monocots, orchid (Oncidium Gower Ramsey) and lily (Lilium longiflorum), exhibit different effects on floral transition and formation in Arabidopsis thaliana. Plant Cell Physiol. 2010;51(6):1029-45.

48. Wu W, Chen F, Jing D, Liu Z, Ma L. Isolation and characterization of an AGAMOUS-like gene from Magnolia wufengensis (Magnoliaceae). Plant Mol Biol Report. 2012;30(3):690-8.

49. Su S, Shao X, Zhu C, Xu J, Tang Y, Luo D, Huang X. An AGAMOUS-like factor is associated with the origin of two domesticated varieties in Cymbidium sinense (Orchidaceae). Horticulture Res. 2018;5(1):48.

50. Tzeng T-Y, Chen H-Y, Yang C-H. Ectopic expression of carpel-specific MADS box genes from lily and lisianthus causes similar homeotic conversion of sepal and petal in Arabidopsis. Plant Physiol. 2002;130(4):1827-36.

51. Goodrich J, Puangsomlee P, Martin M, Long D, Meyerowitz EM, Coupland G. A Polycomb-group gene regulates homeotic gene expression in Arabidopsis. Nature. 1997;386(6620):44.

52. Lopez-Vernaza M, Yang S, Müller R, Thorpe F, De Leau E, Goodrich J. Antagonistic roles of SEPALLATA3, FT and FLC genes as targets of the polycomb group gene CURLY LEAF. PLoS One. 2012;7(2):e30715.

53. Fernandez DE, Wang C-T, Zheng Y, Adamczyk BJ, Singhal R, Hall PK, Perry SE. The MADS-domain factors AGAMOUS-LIKE15 and AGAMOUS-LIKE18, along with SHORT VEGETATIVE PHASE and AGAMOUS-LIKE24, are necessary to block floral gene expression during the vegetative phase. Plant Physiol. 2014;165(4):1591-603.

54. Pajoro A, Madrigal P, Muiño JM, Matus JT, Jin J, Mecchia MA, Debernardi JM, Palatnik JF, Balazadeh S, Arif M. Dynamics of chromatin accessibility and gene regulation by MADS-domain transcription factors in flower development. Genome Biol. 2014;15(3):R41.

55. Zeng X, Liu H, Du H, Wang S, Yang W, Chi Y, Wang J, Huang F, Yu D. Soybean MADS-box gene GmAGL1 promotes flowering via the photoperiod pathway. BMC Genomics. 2018;19(1):51.

56. Koyama T, Mitsuda N, Seki M, Shinozaki K, Ohme-Takagi M. TCP transcription factors regulate the activities of ASYMMETRIC LEAVES1 and miR164, as well as the Auxin Response, during differentiation of LEAVES in Arabidopsis. Plant Cell. 2010;22(11):3574-88.

57. Liu D, Song Y, Chen Z, Yu D. Ectopic expression of miR396 suppresses GRF target gene expression and alters leaf growth in Arabidopsis. Physiol Plant. 2009;136(2):223-36.

58. He Y, Ning G, Sun Y, Hu Y, Zhao X, Bao M. Cytological and mapping analysis of a novel male sterile type resulting from spontaneous floral organ homeotic conversion in marigold (Tagetes erecta L.). Mol Breed. 2010;26(1): 19-29. 
59. Zahn LM, Kong H, Leebens-Mack JH, Kim S, Soltis PS, Landherr LL, Soltis DE, Depamphilis CW, Ma H. The evolution of the SEPALLATA subfamily of MADS-box genes: a preangiosperm origin with multiple duplications throughout angiosperm history. Genetics. 2005;169(4):2209-23.

60. Zhang JY, Qiao YS, Lv D, Gao ZH, Qu SC, Zhang Z. Malus hupehensis NPR1 induces pathogenesis-related protein gene expression in transgenic tobacco. Plant Biol. 2012;14:46-56.

61. Clough SJ, Bent AF. Floral dip: a simplified method for agrobacteriummediated transformation of Arabidopsis thaliana. Plant J. 1998;16(6):735-43.

62. Zhang S, Lu S, Yi S, Han H, Liu L, Zhang J, Bao M, Liu G. Functional conservation and divergence of five SEPALLATA-like genes from a basal eudicot tree, Platanus acerifolia. Planta. 2017;245(2):439-57.

\section{Publisher's Note}

Springer Nature remains neutral with regard to jurisdictional claims in published maps and institutional affiliations.

- fast, convenient online submission

- thorough peer review by experienced researchers in your field

- rapid publication on acceptance

- support for research data, including large and complex data types

- gold Open Access which fosters wider collaboration and increased citations

- maximum visibility for your research: over $100 \mathrm{M}$ website views per year

At $\mathrm{BMC}$, research is always in progress.

Learn more biomedcentral.com/submissions 